\title{
COURSES AND SEMINARS FOR THE NATIONAL SOCIETIES \\ First-aid experts from African National Societies hold seminar
}

From 25 to 30 April a seminar of first-aid experts from African National Societies was held in Las Palmas, Spain. Nineteen National Societies from French-, Spanish- and Portuguese-speaking countries, were represented.

The seminar was organized by the Spanish Red Cross in co-operation with the French, Portuguese, Belgian and Federal German National Societies, the League and the ICRC. Its purpose was to prepare the table of contents of a first-aid handbook intended for Africa as a whole, to discuss the technical matters involved and to appoint an editorial board.

The organizers first listened to what each National Society wished to do, then collated the replies so that at the plenary meetings the representatives could focus their attention on points about which there were differences of opinion. This procedure finally produced agreement on all points.

The process of consultation will continue, with the various chapters being sent out to all the participants for their comments. Thus the final version will be the result of consensus. We welcome this new departure in co-operation which marked the seminar and which one participant called "the spirit of Las Palmas".

In addition to the chapters on purely technical matters, the handbook will contain a chapter on the Red Cross (principles, organization, history, basic rules of international humanitarian law) and will deal with more specific matters such as the emblem and the rights and duties of first-aid workers in the event of armed conflict.

It is hoped that this handbook will lead to the standardization of first-aid practices and hence to the granting of diplomas recognized throughout the continent.

It would be beneficial if National Societies which did not take part in the Las Palmas seminar could also participate in the consultation process. 